\title{
Influence of Vibration on Golgi Tendon Organ and Hold-Relax of PNF on Muscular Activity and Gait Factors on Delayed Onset Muscle Soreness
}

\begin{abstract}
The purpose of this study was to investigate the effects of vibration on Golgi tendon organ(GTO) and Hold-Relax of PNF in muscular activity and gait factors on Delayed Onset Muscle Soreness(DOMS). This study was conducted on 20 subjects. they were divided into two groups; Hold-Relax of $\operatorname{PNF}(n=10)$, Vibration on $\mathrm{GTO}(n=10)$. Both of the group was performed interventions 1 times a day for 3 days. The data was analyzed by the repeated-ANOVA for comparing before, after $24 \mathrm{~h}$ and after $48 \mathrm{~h}$ changes of factors in each group and the Independent t-test for comparing the between groups. The results are as follows. There was statistically significant difference of before, after $24 \mathrm{~h}$ and after $48 \mathrm{~h}$ vibration on GTO group and Hold-Relax of PNF group in muscular activity and gait factors on DOMS.(p<0.05). There was no statistically significant difference of between vibration on GTO group, but there was statistically significant difference Hold-Relax of PNF group in EMG, step width, step length, stride length(p>0.05). As a results of this study, Hold-Relax of PNF group are effective in improving muscular activity and gait factors.
\end{abstract}

Key words: Delayed Onset Muscle Soreness(DOMS); Vibration on GTO; HoldRelax of PNF; Muscular Activity; Gait Factors

\author{
Hyun ju Juna, Hoe Song Yang, \\ Young Dae Yoo, So Hui Parka, \\ Hyuk Jegal ${ }^{a}$, Chan Joo Jeonga \\ ${ }^{a}$ Cheongam College, Suncheon, Korea \\ Received : 7 June 2015 \\ Revised : 12 July 2015 \\ Accepted : 03 August 2015 \\ Address for correspondence \\ Chan Joo Jeong, MS. \\ Department of Physical Therapy, \\ Cheongam College, 1641 Noksaek-ro, \\ Suncheon, Korea \\ Tel: 82-61-740-7234 \\ E-mail: jeong@scjc.ac.kr
}

\section{INTRODUCTION}

The population can experience a uncomfortable sense or pain on their muscle after performed sudden exercise because they participate sport and leisure activity due to higher economic level recently(1).

Among them, especially Knee injury is frequent as a result of a sudden exercise. Rehabilitative approach is emphasized a strength exercise to ligament and muscles around knee for recovering the function and stability(2).

Muscle pain is the most common musculoskeletal symptoms among those symptoms. It is caused by macro trauma such as sprain, strain, and also caused by micro trauma as muscle injury due to excessive exercises(3).

Delayed Onset Muscle Soreness(DOMS) refers to uncomfortable symptom including pain with limited of motion, muscle weakness after muscle strength exercise which is not familiar for body.
Especially DOMS appears after excessive eccentric type of exercise(4). Furthermore, the symptoms of DOMS are the stiffness sense and loss of mobility, power production, flexibility, range of motion or tenderness as palpation in junction of muscle and tendon, and more sensibility tends to relate with high exercise intensity(5). Specifically. DOMS induces as a result damaged twitch fibers selectively due to sudden high intensity eccentric type of exercise(6). like a putting heavy objects down, heavy force loading on muscle fiber and connective tissues can make a eccentric contraction.

In this process, especially frequency of DOMS is high when using resistance is overloading or not familiar on muscles(7). According to the previous research, due to the damage of muscle induced eccentrically, its loss of strength is worse than concentric or isometric contraction(8). The muscle caused by eccentric contraction induce some phenomenon including muscle fiber, which is related with augmented permeability and reducing power 
production(9). Injury is a result the inflammatory reaction on cellular membrane of muscle caused by eccentric excessive exercise. therefore, given impact to muscle while eccentric movement can cause the DOMS(10).

DOMS appears after $12 \sim 24 \mathrm{hr}$ to finish the severe exercise. after time, the symptoms of DOMS is being severe. It is maximized after 24 48hr(11). after eccentric exercise, there are shown that gait function, center of body and tenderness threshold are diminished or $\mathrm{LDH}$, CK as indicator of muscular impairment due to muscular injury is increased(12).

Proprioceptive Neuromuscular Facilitation(PNF) is one of therapeutic exercise which can be combined functional diagonal exercise patterns for improving neuromuscular function and its reaction(13). Techniques can be used for stability, facilitation for mobility, control of muscle and coordinative movement including muscle strength and endurance. For recovering and facilitating reaction or strengthening, it can be used to stimulate a many of sensory while exercise can be performed(11). Hold and relax, which is one of PNF technique, can be used the isometric contraction. These implied stimulation induce tension of tendon. the tension conducts to anterior horn cell by afferent nerve fiber on GTO. and it contracts muscle. Especially synergist is inhibited and antagonist is activated by interneuron. That is an autogenic inhibition(6). According to previous study, The hold and relax has shown that there is improved the level of fatigue, reduce the pain, incline range of motion among the symptoms of DOMS(6). Related pain and uncomfortable sense of DOMS are most severe on junction of muscle and tendon generally(14). The ending of sensory nerve Ib which was attached, encapsulated by collagen bundle in GTO, slightly bending in stable condition, and then, collagen bundle is tauted and GTO is excited as muscular tension is increased because skeletal muscle contracts. Activation of GTO can be inhibited the response of contraction induced by muscle spindle(15).

The previous study had confirmed that there is reduced the excitability of spinal neuron as applied vibration on muscle which has a spasticity(16). It can be concluded that performed vibration exercise can be reduced pain scale and regaining muscle strength due to pain and weakness of DOMS after maximal stretching exercise(4).

Therefore, the purpose of this study was analysed muscular activity and gait factors on DOMS patient who has a pain on their quadriceps femoris through Hold-relax and vibration on GTO before intervention, after $24 \mathrm{hr}, 48 \mathrm{hr}$. It was also investigated the effects of muscular activity from eccentric contraction by these intervention.

\section{METHODS}

\section{Subjects}

20 female university students in suncheon city were participated in this study, and they had pain which their VAS is over 6 caused by excessive exercise. The groups were divided into two. one was 10 members, who can be conducted vibration on Golgi tendon organ(GTO), and other group was also 10 who can be conducted Hold-relax of PNF.

The characteristics subject of this study were follows(Table 1).

(1) subject has no history and functional disability about influencing of this study.

(2) no psychologic disease.

(3) subject has not to be treated physical therapy from any disease within 6 month.

(4) subject can communicate, understand and perform an requirement

(5) subjects agree experimental procedures of this study.

(6) subjects has over 6 of pain VAS caused by excessive exercise.

Table 1. General characteristics of subjects.

\begin{tabular}{lccc}
\hline & Age(years) & Weight $(\mathrm{kg})$ & Height $(\mathrm{cm})$ \\
\hline Group 1 $(\mathrm{n}=10)$ & $20 \pm 0.00$ & $51.9 \pm 5.86$ & $158.2 \pm 4.52$ \\
Group 2(n=10) & $20 \pm 0.00$ & $52.9 \pm 6.64$ & $162.5 \pm 4.88$ \\
\hline
\end{tabular}

\section{Measurement Tools and Measuring Methods}

The subject was conducted the intervention during 2 days on subject's quadriceps femoris to use the vibration on GTO and Hold-realx of the PNF. In order to release the quardiceps femoris which has a DOMS, Vibration $(20 \mathrm{~Hz})$ applied during 5 minutes after $24 \mathrm{hr}$, after $48 \mathrm{hr}$. In supine, subject had a pillow under the knee for completing releasing. 
The Hold-relax of the PNF was conducted with bended knee on prone position with hard mat. The examiner bent subject's knee until not to complain a pain. In order to avoid pain from protective muscle guarding, the examiner provided resistance not to extend to subjects' knee as holding. After causing DOMS, The intervention after $24 \mathrm{hr}$, and $48 \mathrm{hr}$, respectively, was carried out for 5 minutes.

EMS is a test which can detect electro activity of muscle. In other words, this device can be detected electrical change to muscular reaction for nerve stimulation. it is very useful to assess the functional statues of skeletal muscle and as noninvasive device(17).

In order to measure for muscular activity, vibration group was measured in the supine posture to give force to the leg. In hold relax group, the resistance were given to bending the leg in the prone position. The measurement immediately DOMS inducing and after $24 \mathrm{hr}, 48 \mathrm{hr}$ were done. In order to measure the step width, step length, stride length, The subjects walked on the treadmill three times in total while they are walking on the treadmill for 30 seconds.

\section{Data Analysis}

Test for significance was analyzed by repeatedmeasured ANOVA within groups and, If there is a difference between the measured period of each group, Repeated contrast test was analyzed for significant. Level of significance was set at $\alpha=.05$.

\section{RESULTS}

\section{The Change of Vastus Medialis Activity according to Period}

As a result of repeated analysis for vastus medialis activity on Group1 and Group2(Table 2), there was no significant different the measurement $\operatorname{period}(\mathrm{P}\rangle .05)$.

\section{The Changes of Vastus Lateralis Activity accord- ing to Period}

As a result of repeated analysis for vastus lateralis activity on Group 1 and Group 2(Table 2), there was no significant different according to $\operatorname{period}(\mathrm{P}\rangle .05)$.

\section{The Change of Rectus Femoris Activity according to Period}

As a result of repeated analysis for vastus medialis activity on Group 1 and Group 2, there was a significance different according to period( $\mathrm{P}<.05)$. There was no significance difference after $24 \mathrm{hr}$, $48 \mathrm{hr}$ at Group 1(p $>$.05). however, in Group 2, there was a significance different after $24 \mathrm{hr}(\mathrm{P}<.05)$ but no different after $48 \mathrm{hr}(\mathrm{p}\rangle .05)$ (Table 2).

\section{The Change of Step Width according to Period}

As a result of repeated analysis for step width on Group 1 and Group 2(Table 6)(Table 3), there was no significant different the measurement $\operatorname{period}(\mathrm{P}\rangle .05)$,

\section{The Change of Step Length according to Period}

As a result of repeated analysis for step length on vibration on Group 1 and Group 2(Table 3), there was significant different the measurement $\operatorname{period}(\mathrm{P}\rangle .05)$.

There was no significance different after $24 \mathrm{hr}$, $48 \mathrm{hr}$ at Vibration on GTO(p $>$.05). There was no significance different after $24 \mathrm{hr}, 48 \mathrm{hr}$ on right side of HR group(p $>.05)$ there was a significance different after $24 \mathrm{hr}(\mathrm{P}<.05)$ on left side but no different after $48 \mathrm{hr}(\mathrm{p}\rangle .05)$ (Table 3)..

\section{The Change of Stride Length according to Period}

As a result of repeated analysis for stride length on vibraion on Group 1 and Group 2, there was no significant different the measurement period(P>.05)(Table 3). 
Table 2 Changes of muscle activity according to period

\begin{tabular}{ccccccc}
\hline \multirow{2}{*}{$\begin{array}{c}\text { Pulmonary } \\
\text { function }\end{array}$} & \multicolumn{2}{c}{ Pre } & \multicolumn{2}{c}{24 hours } & \multicolumn{2}{c}{48 hours } \\
\cline { 2 - 6 } & Group 1 & Group 2 & Group 1 & Group 2 & Group 1 & Group 2 \\
\hline Vastus medialis $(\mu \mathrm{V})$ & $0.64 \pm .31$ & $0.84 \pm 1.01$ & $0.92 \pm .66$ & $0.54 \pm .20$ & $1.01 \pm .83$ & $0.68 \pm .38$ \\
Vastus lateralis $(\mu \mathrm{V})$ & $0.80 \pm .31$ & $0.64 \pm .27$ & $1.01 \pm .73$ & $0.67 \pm .28$ & $1.24 \pm 1.17$ & $0.75 \pm .39$ \\
Rectus femoris $(\mu \mathrm{V})$ & $0.86 \pm .26$ & $0.67 \pm .33$ & $0.77 \pm .53$ & $0.37^{*} \pm .19$ & $0.90 \pm .61$ & $0.43 \pm .35$ \\
\hline
\end{tabular}

Mean $\pm S D$

Significance was tested by repeated-ANOVA(* $\left.{ }^{*}<.05\right)$

Group 1: Vibration Treatment of GTO Group 2: Hold-relax of PNF

Table 3. Changes of gait factors according to period

\begin{tabular}{|c|c|c|c|c|c|c|c|c|c|c|c|c|}
\hline \multirow{3}{*}{$\begin{array}{l}\text { Pulmonary } \\
\text { function }\end{array}$} & \multicolumn{4}{|c|}{ Pre } & \multicolumn{4}{|c|}{24 hours } & \multicolumn{4}{|c|}{48 hours } \\
\hline & \multicolumn{2}{|c|}{ Group 1} & \multicolumn{2}{|c|}{ Group 2} & \multicolumn{2}{|c|}{ Group 1} & \multicolumn{2}{|c|}{ Group 2} & \multicolumn{2}{|c|}{ Group 1} & \multicolumn{2}{|c|}{ Group 2} \\
\hline & $\mathrm{R}$ & $\mathrm{L}$ & $\mathrm{R}$ & L & $R$ & L & $\mathrm{R}$ & L & $\mathrm{R}$ & $L$ & $\mathrm{R}$ & $L$ \\
\hline $\begin{array}{l}\text { sSep width } \\
\text { (mm) }\end{array}$ & $\begin{array}{l}85.90 \\
\pm 7.71\end{array}$ & $\begin{array}{l}83.54 \\
\pm 7.52\end{array}$ & $\begin{array}{l}85.73 \\
\pm 5.52\end{array}$ & $\begin{array}{l}90.29 \\
\pm 7.06\end{array}$ & $\begin{array}{l}84.87 \\
\pm 7.67\end{array}$ & $\begin{array}{l}88.21 \\
\pm 4.88\end{array}$ & $\begin{array}{l}81.42 \\
\pm 10.01\end{array}$ & $\begin{array}{l}88.63 \\
\pm 8.42\end{array}$ & $\begin{array}{l}84.36 \\
\pm 11.88\end{array}$ & $\begin{array}{l}89.35 \\
\pm 5.00\end{array}$ & $\begin{array}{l}80.87 \\
\pm 12.5\end{array}$ & $\begin{array}{l}87.09 \\
\pm 7.21\end{array}$ \\
\hline $\begin{array}{l}\text { Step length } \\
(\mathrm{mm})\end{array}$ & $\begin{array}{l}220.34 \\
\pm 49.72\end{array}$ & $\begin{array}{l}212.92 \\
\pm 17.93\end{array}$ & $\begin{array}{l}219.09 \\
\pm 26.63\end{array}$ & $\begin{array}{l}214.36 \\
\pm 19.65\end{array}$ & $\begin{array}{l}227.45 \\
\pm 36.57\end{array}$ & $\begin{array}{l}218.82 \\
\pm 14.83\end{array}$ & $\begin{array}{l}221.83 \\
\pm 33.22\end{array}$ & $\begin{array}{l}236.00^{*} \\
\pm 25.03\end{array}$ & $\begin{array}{l}233.25 \\
\pm 51.17\end{array}$ & $\begin{array}{l}220.62 \\
\pm 17.39\end{array}$ & $\begin{array}{c}261.41 \\
\pm 59.07\end{array}$ & $\begin{array}{l}232.01 \\
\pm 26.72\end{array}$ \\
\hline $\begin{array}{l}\text { Stride length } \\
\quad(\mathrm{mm})\end{array}$ & $\begin{array}{l}410.60 \\
\pm 61.44\end{array}$ & $\begin{array}{l}457.50 \\
\pm 90.74\end{array}$ & $\begin{array}{l}384.10 \\
\pm 56.32\end{array}$ & $\begin{array}{l}438.40 \\
\pm 73.55\end{array}$ & $\begin{array}{l}437.50 \\
\pm 45.14\end{array}$ & $\begin{array}{l}419.70 \\
\pm 49.39\end{array}$ & $\begin{array}{l}398.30 \\
\pm 51.34\end{array}$ & $\begin{array}{l}416.70 \\
\pm 35.42\end{array}$ & $\begin{array}{l}402.10 \\
\pm 77.19\end{array}$ & $\begin{array}{l}404.70 \\
\pm 100.11\end{array}$ & $\begin{array}{l}380.20 \\
\pm 63.39\end{array}$ & $\begin{array}{l}425.00 \\
\pm 54.31\end{array}$ \\
\hline
\end{tabular}

Mean $\pm S D$

Significance was tested by repeated-ANOVA $\left({ }^{*} p<.05\right)$

Group 1: Vibration Treatment of GTO

Group 2 : Hold-relax of PNF

\section{DISCUSSION}

Vibration on GTO and Hold-relax was conducted to subjects who has a DOMS in quadriceps femoris for influencing the muscular activity and gait factors and analysis time was after $24 \mathrm{hr}, 48 \mathrm{hr}$ in this study.

There had been a significant decrease the muscular activity of recuts femoris after $24 \mathrm{hr}$, but it had increased after $48 \mathrm{hr}$ in hold relax group. and vastus medialis, vastus lateralis were not a significant. Bae has confirmed that applied vibration and stretching stimulation inhibit the excitatory of spinal motor neuron on agonist which can appear the spasticity on upper limb, and thereby spasticity was declined(16). Go has reported that applied vibrative stimulation exercise helps to recover of muscular function(18).

There are intervention to whole body vibration for muscle strengthening(19). Jin et al. has reported that whole body vibration exercise on the platform can affect the effect of exercise by con- ducting the vibration sense on specific area of body and whole body(20).

Kim et al. has reported that even though circumference of triceps surae doesn't show significant difference between vibration training group, according to the measurement time, there is a significance difference within groups(21). there was no significance different for reducing at increased muscle tension due to DOMS at Vibration on GTO in this study.

however, even though mean of rectus femoris had been diminished after $24 \mathrm{hr}$, muscular activity was increased on original level.

if change of vibration intensity with various intervention is added, the result can be expected positively.

Borje et al. has reported that vibration exercise was conducted to public and an athletics for comparing with traditional training, there are less effort and time on training effects(22). Cardinal and bosco has reported that the value of increased activity to surface EMG is much more muscle 
strengthening exercise with vibration than only muscle strength exercise. Intervention of vibration can be suggested reducing aging on musculoskeletal structures and improving the performance(23). Even though gait factors was increased in HR group after $24 \mathrm{hr}$, especially left step length after $48 \mathrm{hr}$, there was no significant difference in this study. HR technique had been shown positive effect. Lee has reported that HR technique with TENS for treatment of DOMS, which can make a eccentric excessive exercise, had effected increase of Range of motion and relief the pain on elbow joint(6).

In this study, There were short intervention applied period, time and subjects were also limited and not control subjects' daily living as a result, unknown variation could be affects the results, and there was no muscular activity after $72 \mathrm{hr}$. so this study did not suggest whether to return the value of their normal muscular activity. Because any intervention had been applied not to DOMS, it was unknown to compare between applied group or not.

Aggregatively, HR of PNF has shown a significance different in muscular activity and gait factor rather than vibration on GTO. In the specific muscle, espeically rectus femoris has only different than others. Karoline et al. has reported that therapeutic interventions, which it can be reduced the increased muscular tension, include the icing, stretching, electrical stimulation, ultrasound, massage(24). It complements the interventions of previous research, and the program can be need not only to strength for muscle but also muscular relaxation.

\section{CONCLUSION}

This subjects was university female students and they had a DOMS which subject can feel over 6 uncomfortable sense, and then the intervention was conducted. The vibration on GTO and HR were conducted on DOMS and then, Muscular activity and gait factors were measured after $24 \mathrm{hr}, 48 \mathrm{hr}$ in this study.

According to measurement period for muscular activity and gait factors in each groups, there was no significant difference in vibration on GTO.

HR group had a significant difference in muscular activity of rectus femoris. as well as step length of left in gait factors.
Therefore, HR techniques has shown positive effect in muscular activity and gait factors. and if the HR is applied in abnormal increased tension of skeletal muscle, it also can be expected positive effects. we need not only to develop the muscular intervention for strengthening but also release for muscle relaxation.

\section{REFERENCES}

1. Aramstrong RB. Mechanism of exercise induced delayed onset muscular soreness. Medicine and Sicence in Sports and Exercise 1984; 16(6):529538.

2. Kim HS. Study of the Effective Hip Joint Angle During Quadriceps Isometric Exercise By Electromyographic Analysis. Graduate School of Kyung Hee University, Master' s thesis 2001..

3. Kim BJ. Effects of Pre-eccentric Exercise for Delayed Onset Muscle Soreness and Muscle Function Rehabilitation. Graduate School of Dongshin University, Master' s thesis 2008.

4. Song HH. Effect of local vibration treatment on recovery from Delayed Onset of Muscle Soreness. Graduate School of Sports Industry Kook Min University, Master' s thesis 2010.

5. Cheung K, Hime PA, Maxwell L. Delayed Onset Muscle Soreness. sports medicine 2003; 33(2):145-164.

6. Lee SY. Effects of hold-relax with agonist contraction action and TENS on delayed onset muscle. Graduate School of Yunsei University, Doctorial thesis 2006.

7. Park RJ, Kim EY, Kim KJ, Jang JH. The Effect of Therapeutic Methods after Artificial DOMS on Subjective Pain Scale and Muscular Functions. Journal of Special Education \& Rehabilitation Science 2009; 48(3)151-169.

8. Sellwood KL, Brukner P, Williams D, Nicol A, Hinman R. Ice water immersion and delaydonset muscle soreness; a randomised controlled trial. Br J Sports Med 2007; 41(6):392-39741.

9. Willems ME, Hale T, Wilkinson CS. Effect of manual massage on muscle specific soreness and single leg jump performance after downhill treadmill walking. Medicina Sportiva 2009; 13(2):61-66.

10. Arab AM, Salavati M, Ebrahimi, I, Mousavi ME. Sensitivity, specificity and predictive value of the clinical trunk muscle endurance tests in low back pain. Clinical rehabilitation 2007; 21(7):640-647. 
11. Kisner C. Colby LA.. Therapeutic exercise: foundations and techniques, 6th Ed. Philadelphia, FA Davis 2012.

12. Yu JY. The Influence of Microcurrent Stimulation Intensity on Symptom Occurrence and COP and Gait Parameters after Eccentric Contraction Exercise. Graduate School of Nambu University Master' s thesis 2013.

13. Han SW, Chang CH, Yoon BC, Yoo BG, Lee KJ, Lee $\mathrm{MH}$. The Change of Cardiopulmonary Function by Physical Therapy and Rehabilitation Exercise during 8-weeks in Patient with Patellofemoral Pain Syndrome. Journal of KSSPT 2005; 1(1):17-24.

14. Cleary M A, Sweeney L A, Kendrick Z V, Sitler MR. Dehydration and symptoms of delayed-onset muscle soreness in hyperthermic males. Journal of athletic training 2005; 40(4):288-297.

15. Min GO. Therapeutic Exercise for Musculoskeletal Syseem. Korea, Sky tteurak 2012.

16. Bae SH. The Effects of stretch and, vibratory stimulation on the excitability of the spinal alpha motor neurones in patients with upper limb spasticity. Graduate School of Dongshin University, Master' s thesis 2011.

17. Jeong JG. Quantitative Evaluation of Normal Skeletal MuscleUsing Ultrasound Image and Surface Electromyography. Graduate School of Dongshin University, Doctorial thesis 2005.
18. Koh HW. Effect of Vibratory Stimulation on Recovery of Muscle function from Delayed Onset Muscle Soreness. Graduate School of Dongshin University, Master' s thesis 2011.

19. Rees SS, Murphy AJ, Watsford ML. Effects of whole-body vibration exercise on lower-extremity muscle strength and power in an older population: a randomized clinical trial. Physical therapy 2008; 88(4):462-470.

20. Jin SJ, Lee JH, Lee DT, Lee MC.. Review of the influence of whole body vibration exercise on muscular function, neuroskeletal system, and body composition. Halth \& Sports Medicine : Official Journal of KACEP 2007; 9(1):31-38.

21. Kim ES, Kim MH, Cho YM, Lee WH. The Effect of Vibration Training Pre-eccentric Exercise on Delayed Onset Muscle Soreness of Triceps Surae. Journal of the Korea Academia-Industrial cooperation Society 2011; 12(12):5789-5796.

22. Rehn B, Nilsson P, Norgren M. Effects of wholebody vibration exercise on human bone density-systematic review. Physical Therapy Reviews 2008; 13(6):427-433.

23. Cardinale M, Bosco C. The use of vibration as an exercise intervention. Exercise and sport sciences reviews 2003; 31(1):3-7.

24. Cheung K, Hume PA, Maxwell L. Delayed onset muscle soreness. Sports Medicine 2003; 33(2):145164. 